\title{
THE IMPACT OF GENDER ON CHILD DENTAL ANXIETY IN A SAMPLE OF EGYPTIAN CHILDREN (A CROSS-SECTIONAL STUDY)
}

\author{
Ann E Gaber ${ }^{1} B D S$, Amani M Khalil ${ }^{2} D S c$, Dalia M Talaat ${ }^{3} P h D$
}

\begin{abstract} - Dental Subscale (CFSS-DS). were very anxious. Girls were significantly more dentally anxious than boys. $(\mathrm{p}=0.02)$. identified as the most fearful item in the dental visit.

KEYWORDS: Dental anxiety, dental fear, child gender, CFSS-DS

Dentist, Ministry of Health, Alexandria, Egypt.

Professor of Pediatric Dentistry, Faculty of Dentistry, Alexandria University, Alexandria, Egypt.

Associate Professor of Pediatric Dentistry, Faculty of Dentistry, Alexandria University, Alexandria, Egypt.
\end{abstract}

INTRODUCTION: Despite the recent developments in the dental equipment and treatment procedures, dental fear and anxiety (DFA) are relatively common among children and adults. Relating dental fear and anxiety to gender is a controversial issue in scientific literature. OBJECTIVES: The aim of this study is to examine the impact of gender on the child's dental anxiety in a sample of Egyptian children. MATERIALS AND METHODS: One hundred and twenty-six children 6-10 years old (60 boys and 66 girls), at the Department of Pediatric Dentistry, Faculty of Dentistry Alexandria University were asked to participate in the study. Children answered the Child Fear Survey Schedule

RESULTS: About forty-six percent of the children in the studied sample were non-anxious, $30.2 \%$ were potentially anxious and only $23 \%$

CONCLUSIONS: The level of DFA was affected by the child gender where girls were more dentally anxious than boys. Injection was

\section{INTRODUCTION}

In the dental practice, one of the most stressful challenges that face the dental team is the treatment of dentally anxious patients. These patients often manifest their anxiety in the form of disruptive behavior during the dental visit (1). Dental anxiety or dental fear is an inevitable emotion rising as a reaction to the stress generated by various dental procedures (2). Although dental anxiety and fear are often used as equivalents in literature, differences can be distinguished. Anxiety refers to an aversive emotion in which the source of the threat is ill defined or not immediately present. On the other hand, fear refers to a reflex action to threatening stimuli experienced within the dental situation (3). Despite this differentiation between fear and anxiety, scientists could not overcome their existing overlap in the underlying brain and behavioral mechanisms. For this reason, the expression dental fear anxiety (DFA) has been proposed to include all forms of dental fear as well as dental anxiety (4). To sum up, DFA has been recommended for use as an umbrella term in this research.

A review of studies in children by Kleinberg et al (5) found the estimates of DFA in children range from $5.7 \%$ to $19.5 \%$ irrespective of child's nationality or cultural background. Additionally, Smith et al (6) conducted a review of studies to explore the prevalence of DFA across the years. Surprisingly, they found stability in the level of DFA over the last 50 years despite the modern advances in dental care aiming to alleviate DFA and pain.

The onset of DFA had been proven to be in early childhood (7). Older children may also suffer from DFA which declines towards adolescence (8). This descend of DFA is accredited to the rise in the ego strength accompanied by the development of metacognition preparing the child to use different coping styles (5).

Rachman's (9) three-pathway theory is the most widely employed theory for the development of DFA. Classical conditioning is the first pathway in which DFA acquisition is related to the child's own negative past dental experiences.
The second pathway for DFA development is indirectly through vicarious learning. This means the negative information gained from close relatives, friends, by internet or television. The third pathway is modeling, for example, when children observe a friend or relative reacting anxiously to a dental situation.

As the three-pathway theory is not enough to explain the acquisition of DFA, research has focused on additional factors in the etiology of dental anxiety (10). For example; child general shyness and fearfulness (6), child tendency toward negative emotionality (11), coping ability of children (12) and child's temperament (13).

People with high DFA can suffer a wide range of side effects that can be summarized into five main categories. These categories include the physiological, cognitive, behavioral, health and social effects (14). The physiological impacts can be manifested as dry mouth, sweatiness, and increased heart rate before and during the dental appointment. As for the cognitive implications, patients with higher level DFA may also suffer from negative thoughts, fear, crying, aggression, sleep disturbances and greater self-medication (15).

Regarding the behavioral impact, it has been proven that about $61 \%$ of children with DFA manifest difficult-tomanage behavior during their dental visit (16). In addition, highly DFA patients tend to show modification of foodrelated behavior. For example, their reduced ability to chew makes them refuse hard food. Also cold foods are avoided to prevent pain elicited by sensitivity (13). Another behavioral influence of DFA is the avoidance of dental care or irregular dental attendance. Highly anxious patients only seek treatment when dental care is unavoidable, due to the experienced pain or the intensity of symptoms (17). This is further proved by Skaret et al (18), who found that patients with avoidance behaviour have more negative beliefs of the dentist and higher dental anxiety compared to non-avoiders.

Considering the impact of DFA on patient's health, greater incidence of caries among highly anxious children 
has been reported (19). Eitner et al (20) found higher DMFT (Decayed Missing Filled Teeth) scores in highly anxious patients. These findings led researchers to the belief in the "vicious cycle dynamic" linking dental anxiety and worsen oral health. This could be explained as the lower or more irregular frequency of dental visits results in a worse dental health and the need for more complicated and painful dental treatment. This would confirm to the patients' anticipated negative expectations about the dental visits and reinforce their dental anxiety, which by its turn intensify the avoidance pattern. Consequently, further damage and deterioration of dental health creating a spiral cycle of dental disadvantages (19).

Failing oral health may outgrow to have social implications of feelings of dissatisfaction with the appearance of their teeth, inferiority and shame (13). This may diminish their confidence, self-esteem, and their relations with peers (21).

Relating DFA to gender is a controversial issue in scientific literature. Different studies show opposite opinions. On one hand, DFA has been linked more to girls than boys as reported by some studies $(22,23)$. In addition, research has high lightened greater incidence and more exaggerated fear in girls compared to boys (3). CarrilloDiaz et al (24) found higher level of DFA in females, accompanied by decline of the oral health related emotional well-being than males. On the other hand, Udoye et al (25) stated that boys' fear is more likely and more common to cause escaping of dental visit. Only few studies showed no significant relationship between DFA and gender $(8,26)$. Thus the present study aimed to evaluate the association between the child's gender and DFA in Egypt. The null hypothesis tested was that, there is no difference in the DFA level between boys and girls.

\section{MATERIALS AND METHODS}

The conducted study was a cross-sectional observational study. A sample size of 126 children and mothers dyads was the enough required sample to detect an effect size of $25 \%$ improvement, as statistically significant with $90 \%$ power and at a significance level of 0.05 . Sample size per group did not need to be increased to control for withdrawal bias. The sample size was calculated using $\mathrm{G}$ Power version 3.1.9.2.

The sample was drawn from children patients attending the Pediatric Dental Department Clinic, Faculty of Dentistry, Alexandria University according to the inclusion criteria that included children of an age range 6-10 years, first dental visit and accompanied by their mothers. Children with previous dental experiences, physical or mental disabilities were excluded from the study. This study was performed after receiving the approval of the Research Ethics Committee in the Faculty of Dentistry, Alexandria University. Participation was fully voluntarily and not conditional to treatment. Parents of the children included in the study were requested to sign an informed consent.

The participated children were divided into two groups, group A (60 boys) and group B (66 girls). Parents and children were approached in the Pediatric Dentistry Department's waiting room. After a brief explanation about the nature and aim of this study, the children were addressed separately, interviewed and asked to answer the questions in Child Fear Survey Schedule-Dental Subscale questionnaire (CFSS-DS) to assess their dental fear. The Arabic version of the CFSS-DS was adapted from the original English version and had been used to assess dental fear in several Arabic speaking countries (28-30). It contained 15 items, the possible item responses were a 5-point Likert scale ranging from 1 (not afraid at all) to 5 (very afraid), giving a range of possible total scores from 15 to 75. The total score was used to categorize children into three groups according to their anxiety level. The child was considered non-anxious if his total score was below thirty-two. If the child scored above thirty-two and below thirty-nine, he was considered as potentially anxious. However, if the child scored above 39, he was considered as a highly anxious patient (29). Some explanations of some questions were given according to the level of the child's cognitive development to ensure the reliability of the questionnaire. Parents were not allowed to assist their children in filling out their questionnaire. Children were given simple gifts to encourage them to participate in the study.

\section{STATISTICAL ANALYSIS}

Intra-examiner reliability test was carried out using kappa test by MedCalc Statistical Software version 14.8.1. Data were analyzed using SPSS Version 21. Data were described using minimum, maximum, mean and standard deviation for the normally distributed data. The Mann-Whitney U test was used to compare differences between two independent groups (sex) when the dependent variable was either ordinal or continuous, but not normally distributed. Box and whisker graph and bar graph were used to describe results.

\section{RESULTS}

Good intra-examiner reliability was achieved with Cronbach's Alpha equal 0.793. The mean age for the participating children was $84.29 \pm 9.421$ months. The mean total CFSS-DS score was $33.04 \pm 8.11$. Data collected in this study found that $46.8 \%$ of the children were non-anxious and $30.2 \%$ were potentially anxious. While only $23 \%$ were highly anxious.

The highest fear scores for the total sample were obtained on the items 'injections' 'chocking', 'having a stranger to touch you' with means (3.69 \pm 1.120$),(2.92 \pm 1.136),(2.75 \pm 1.237)$ respectively. While the least fearful items were 'doctors', 'people in white uniforms' and 'having to open the mouth'

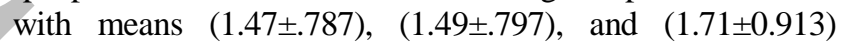
respectively. (Table 1$)$.

No difference in the ranking of the most and least fearful items was found between boys and girls. Both girls and boys choose "injections" and 'chocking' for the most fearful items and 'doctors' for the least fearful item. Girls scored significantly higher mean in all CFSS-DS items than boys $(\mathrm{p}=0.011)$ except for item 12 'chocking' were boys scored higher mean (3.01) and girls scored (2.85). (Table 1) (Fig 1).

Significant difference $(p=0.02)$ was found in the level of DFA in association with sex of the child. Girls' mean (35.30) was higher than boys' (30.55). (Table 2) (Fig 2). In the current study, the percentage of anxious boys was only $15 \%$. On the other hand, the girls scored double the boys for the anxious group (30.3\%). Furthermore, the boys scored as high as $58.33 \%$ on the non-anxious group while the girls were only 34.85\%. (Table 3) (Fig 3). 
Table 1: Mean and standard deviation of 15 items of CFSS-DS for total population, boys and girls.

\begin{tabular}{|c|c|c|c|c|c|c|c|}
\hline \multirow{2}{*}{$\begin{array}{c}\text { How } \\
\text { afraid is } \\
\text { your child } \\
\text { of: }\end{array}$} & \multicolumn{2}{|c|}{ Boys } & \multicolumn{2}{|c|}{ Girls } & \multicolumn{3}{|c|}{ Total } \\
\hline & Mean & S.D. & Mean & S.D. & Mean & S.D. & Median \\
\hline Dentists & 1.983 & 0.93 & 2.11 & 1.165 & 2.05 & 1.057 & 2.00 \\
\hline Doctors & 1.25 & 0.508 & 1.67 & 0.934 & 1.47 & .787 & 1.00 \\
\hline $\begin{array}{c}\text { Injection } \\
\text { shots }\end{array}$ & 3.6 & 1.167 & 3.77 & 1.078 & 3.69 & 1.120 & 4.00 \\
\hline $\begin{array}{c}\text { Having } \\
\text { somebody } \\
\text { examine } \\
\text { your teeth }\end{array}$ & 1.55 & 1.048 & 2.08 & 0.98 & 1.83 & 1.044 & 2.00 \\
\hline $\begin{array}{l}\text { Having to } \\
\text { open your } \\
\text { mouth }\end{array}$ & 15 & 0.746 & 1.85 & 1.026 & 1.71 & .913 & 1.00 \\
\hline $\begin{array}{l}\text { Having a } \\
\text { stranger } \\
\text { touch you }\end{array}$ & 2.67 & 1.310 & 2.83 & 1.171 & 2.75 & 1.237 & 3.00 \\
\hline $\begin{array}{c}\text { Having } \\
\text { somebody } \\
\text { look at you }\end{array}$ & 2.1 & 1.889 & 2.45 & 1.139 & 2.29 & 1.172 & 2.00 \\
\hline $\begin{array}{c}\text { The dentist } \\
\text { drilling }\end{array}$ & 2.13 & 1.016 & 2.636 & 1.002 & 2.40 & 1.036 & 2.00 \\
\hline $\begin{array}{l}\text { The sight } \\
\text { of the } \\
\text { dentist } \\
\text { drilling }\end{array}$ & 1.53 & 0.853 & 2.65 & 1.143 & 2.12 & 1.157 & 2.00 \\
\hline $\begin{array}{l}\text { The noise } \\
\text { of the } \\
\text { dentist } \\
\text { drilling }\end{array}$ & 1.75 & 0.950 & 2.42 & 1.3016 & 2.10 & 1.192 & 2.00 \\
\hline $\begin{array}{c}\text { Having } \\
\text { somebody } \\
\text { put } \\
\text { instruments } \\
\text { in your } \\
\text { mouth } \\
\end{array}$ & 1.95 & 0.872 & 2.136 & 1.188 & 2.05 & 1.050 & 2.00 \\
\hline Chocking & 3.01 & 0.983 & 2.85 & 1.259 & 2.92 & 1.136 & 3.00 \\
\hline $\begin{array}{l}\text { Having to } \\
\text { go to the } \\
\text { Hospital }\end{array}$ & 1.983 & 1.200 & 2.045 & 1.044 & 2.02 & 1.117 & 2.00 \\
\hline $\begin{array}{l}\text { People in } \\
\text { white } \\
\text { uniforms }\end{array}$ & 1.467 & 0.812 & 1.515 & 0.789 & 1.49 & 0.797 & 1.00 \\
\hline $\begin{array}{l}\text { Having the } \\
\text { dentist } \\
\text { clean your } \\
\text { teeth }\end{array}$ & 2.00 & 0.938 & 2.27 & 1.2095 & 2.14 & 1.093 & 2.00 \\
\hline Total & 30.55 & 6.387 & 35.30 & 8.863 & 33.04 & 8.111 & 32.0 \\
\hline
\end{tabular}

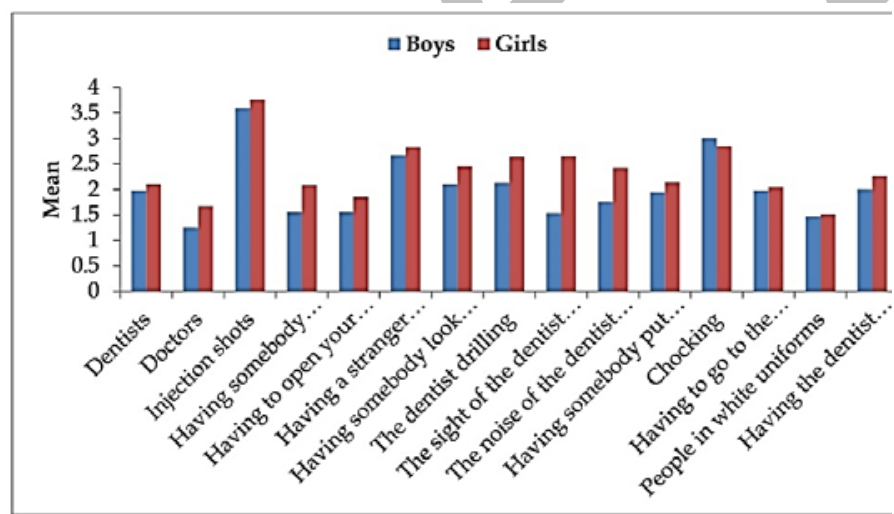

Figure 1: Representation of the means of the 15items of CFSS DS according to sex.

\section{DISCUSSION}

Several methods have been developed to measure DFA (31). Porritt et al (32) in their review of the different measures used to assess DFA proved that the CFSS-DS is the most commonly used psychometric method, which approaches the gold standard for measuring fear in pediatric dental research. Furthermore, the CFSS-DS was originally developed for assessment of dental fear in children. In addition, normative data and cut-off scores have been provided for several countries, enabling comparisons between different study populations and cultures (33).

Children included in the sample were school-aged children with age range from $6-10$ years $(28,29)$. This age group was selected to ensure their cognitive development to be able to understand the questions and provide real answers (34). Furthermore, children were chosen with no previous dental experiences. The reason behind this condition is that past negative dental experiences can elevate DFA (9). While on the other hand familiarizing children with the dental situation, after visiting the dentist more often, can contribute to some decrease in DFA (35).

Table 2: Mean and standard deviation of CFSS-DS in boys and girls.

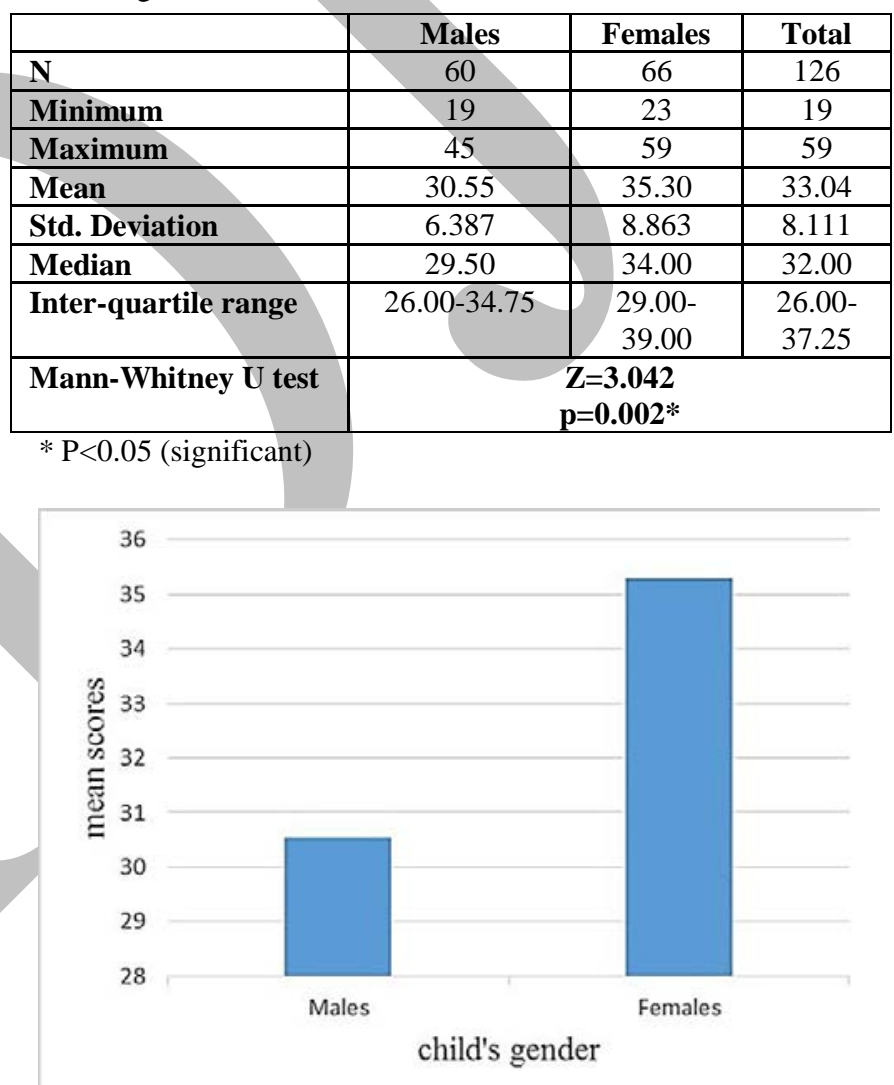

Figure 2: Representation of the mean scores of CFSS-DS according to the sex.

In our study, the Arabic version of CFSS-DS showed good internal consistency, which is consistent with versions in other languages, for which values ranging from 0.78 to 0.92 have been obtained $(19,22)$. In addition, it indicates that the scale is a homogenous and highly reliable method of measuring Egyptian children DFA. Additionally, it indicates that the Arabic questions are very specific and clearly understood by children in this age group, similar to other languages. $(19,31,36)$.

Based on the results of the present study, the null hypothesis was rejected. Significant difference was found in the mean CFSS-DS scores based on the child gender. Girls were more dentally fearful than boys. This difference may reflect cultural considerations, as Egyptian boys are typically raised to be 
brave and are not expected to declare their fears, unlike girls (27). This finding agrees with previous studies that have found higher DFA in girls (22-24). In contrast, some researchers have found no effect of gender on dental fear $(8,26)$.

In the present study the mean CFSS-DS score falls in the range of fear scores $(22.1$ - 33.25) observed by previous study (22). However, another study reported higher mean fear scores of 37.8 and 45.9 for fearful children (30).

The data obtained in the present study showed that the majority of study population showed no DFA. On the other hand, the percentage of children suffering high DFA, which is more likely to interfere with dental treatment, were found to be only $23 \%$. Potentially anxious children were $30.2 \%$. This group of children suffers some degree of dental fear and represents a borderline area for DFA development. Special interest should be given to these children to prevent the development of DFA.

In the current study, the most fearful items on the CFSS-DS were "injections" and “chocking." Most studies have found injections to be ranked highest, with slight differences in other items' rankings $(28,37)$. This indicates that children have similar concerns with dental treatment irrespective of their cultures $(22,29)$. Although girls scored significantly higher fear scores in almost all the items on CFSS-DS, but the items' ranking of the most and least fearful items in the dental visit did not vary according to the sex of the child.

Table 3: Number and percentage of anxious, potentially anxious and anxious children for total population, boys and girls.

\begin{tabular}{|c|c|c|c|c|c|c|}
\hline & \multicolumn{2}{|c|}{ Non anxious } & \multicolumn{2}{c|}{$\begin{array}{c}\text { Potentially } \\
\text { anxious }\end{array}$} & \multicolumn{2}{c|}{ Anxious } \\
\cline { 2 - 7 } & (n) & $(\%)$ & (n) & (\%) & (n) & (\%) \\
\hline Boys & 35 & $58.33 \%$ & 16 & $26.67 \%$ & 9 & $15 \%$ \\
\hline Girls & 23 & $34.85 \%$ & 23 & $34.85 \%$ & 20 & $30.3 \%$ \\
\hline Total & 58 & $46 \%$ & 39 & $31 \%$ & 29 & $23 \%$ \\
\hline
\end{tabular}

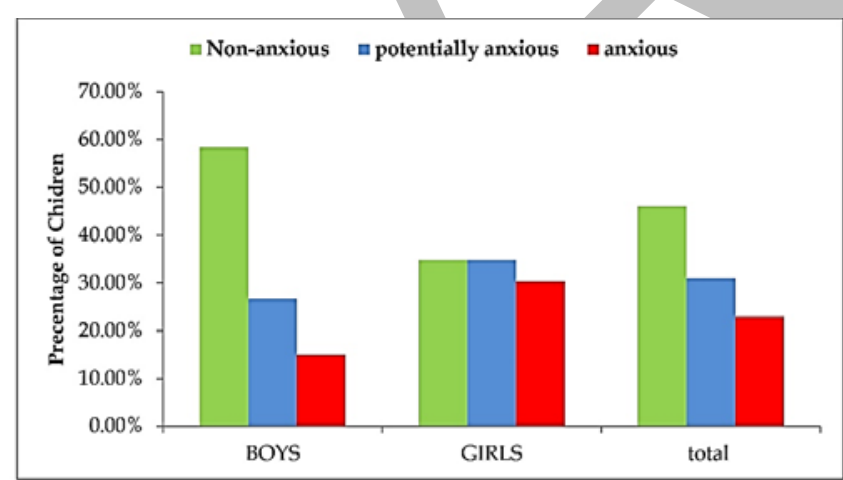

Figure 3: Representation of the percentage of anxious, potentially anxious and anxious children for total population, boys and girls.

\section{CONCLUSIONS}

Based on results of the present study, it has been concluded that girls are more dentally anxious than boys. "Injection" is the most fearful item for both boys and girls.
The authors declare that they have no conflict of interest. REFERENCES

1. Krikken JB, Veerkamp JS. Child rearing styles, dental anxiety and disruptive behavior; an exploratory study. Eur Arch Paediatr Dent. 2008; 9: 23-8.

2. Arslan S, Erta E, Ülker M. The relationship between dental fear and sociodemographic variables. Erciyes Med J. 2011; 33:295-300.

3. Saatchi M, Abtahi M, Mohammadi G, Mirdamadi M, Binandeh ES. The prevalence of dental anxiety and fear in patients referred to Isfahan Dental School, Iran. Dent Res J. 2015; 12:248-53.

4. Nicolas E, Bessadet M, Collado V, Carrasco P, Rogerleroi V, Hennequin M. Factors affecting dental fear in French children aged 5-12 years. Int J Paediatr Dent. 2010; 20:36673.

5. Klingberg G, Broberg AG. Dental fear/anxiety and dental behaviour management problems in children and adolescents: a review of prevalence and concomitant psychological factors. Int J Paediatr Dent. 2007; 17:391406.

6. Smith TA, Heaton LJ. Fear of dental care: are we making any progress? J Am Dent Assoc. 2003; 134:1101-8.

7. Oktay EA, Kocak MM, Sahinkesen G, Topcu FT. The role of age, gender, education and experiences on dental anxiety. Gulhane Med J. 2009;51: 145-8.

8. Raj S, Agarwal M, Aradhya K, Konde S, Nagakishore V. Evaluation of Dental Fear in Children during Dental Visit using Children's Fear Survey Schedule-Dental Subscale. J Clinic Pediatr Dent. 2013; 6:12-5.

9. Carter AE, Carter G, Boschen M, AlShwaimi E, George R. Pathways of fear and anxiety in dentistry: A review. World J Clin Cases. 2014; 2:642-53.

10. Ten Berge M, Veerkamp JS, Hoogstraten J. The etiology of childhood dental fear: the role of dental and conditioning experiences. J Anxiety Disord. 2002; 16:321-9.

11. Krikken JB, Ten Cate JM, Veerkamp JS. Child dental fear and general emotional problems; a pilot study. Eur Arch Paediatr Dent. 2010; 11:283-6.

12. Marsac ML, Funk JB. Relationships among psychological functioning, dental anxiety, pain perception, and coping in children and adolescents. J Dent Child 2008; 75:243-52.

13. Cohen SM, Fiske J, Newton JT. The impact of dental anxiety on daily living. Br Dent J. 2000; 189:385-90.

14. Schuller AA, Willumsen T, Holst D. Are there differences in oral health and oral health behavior between individuals with high and low dental fear? Community Dent Oral Epidemiol. 2003; 31:116-21.

15. Locker D. Psychosocial consequences of dental fear and anxiety. Community Dent Oral Epidemiol. 2003; 31:14451.

16. Goumans C, Veerkamp JS, Aartman IH. Dental anxiety and behavioural problems: what is their influence on the treatment plan? Eur J Paediatr Dent. 2004; 5:15-8.

17. Armfield JM. What goes around comes around: revisiting the hypothesized vicious cycle of dental fear and avoidance. Community Dent Oral Epidemiol. 2013; 41:279-87.

18. Skaret E, Berg E, Kvale G, Raadal M. Psychological characteristics of Norwegian adolescents reporting no likelihood of visiting a dentist in a situation with toothache. Int J Paediatr Dent 2007; 17:430-8.

19. Ten Berge M, Veerkamp JS, Hoogstraten J, Prins PJ. Childhood dental fear in the Netherlands: prevalence and

\section{CONFLICT OF INTEREST}


normative data. Community Dent Oral Epidemiol. 2002; 30:101-7.

20. Eitner S, Wichmann M, Paulsen A, Holst S. Dental anxietyan epidemiological study on its clinical correlation and effects on oral health. J Oral Rehabil. 2006; 33:588-93.

21. Mehrstedt M1, John MT, Tönnies S, Micheelis W. Oral health-related quality of life in patients with dental anxiety. Community Dent Oral Epidemiol. 2007; 35:357-63.

22. Nakai Y, Hirakawa T, Milgrom P, Coolidge T, Heima M, Mori Y, et al. The Children's Fear Survey Schedule-Dental Subscale in Japan. Community Dent Oral Epidemiol. 2005; 33:196-204.

23. Arapostathis KN, Coolidge T, Emmanouil D, Kotsanos N. Reliability and validity of the Greek version of the Children's Fear Survey Schedule-Dental Subscale. Int J Paediatr Dent. 2008; 18:374-9.

24. Carrillo-Díaz M, Crego A, Armfield J, Romero M. The moderating role of dental expectancies on the relationship between cognitive vulnerability and dental fear in children and adolescents. Community Dent Oral Epidemiol. 2013; 41:269-78.

25. Udoye CI, Oginni AO. Oginni FO. Dental anxiety among patients undergoing various dental treatments in a Nigeria teaching hospital. J Contemp Dent Pract. 2005; 6:91-8.

26. Economou GC. Dental Anxiety and Personality: Investigating the Relationship Between Dental Anxiety and Self- Consciousness. J Dent Educ. 2003; 67:970-80.

27. El-Housseiny AA, Farsi NM, Alamoudi NM, Bagher S, El Derwi DA. Assessment for the Children's Fear Survey Schedule-Dental Subscale. J Clin Pediatr Dent. 2014; 39:406.

28. El-Housseiny AA, Alamoudi NM, Farsi NM, El Derwi DA. Characteristics of dental fear among Arabic-speaking children: a descriptive study. BMC Oral Health. 2014; 14:118-25.

29. El-Housseiny AA, Alsadat FM, Alamoudi NM, El Derwi DA, Farsi NM, Attar MM, et al. Reliability and validity of the Children's Fear Survey Schedule-Dental Subscale for Arabic-speaking children: a cross-sectional study. BMC Oral Health. 2016;19: 49-52.

30. Ten Berge M, Veerkamp JS, Hoogstraten J, Prins PJ. On the structure of childhood dental fear, using the Dental Subscale of the Children's Fear Survey Schedule. Eur J Paediatr Dent. 2002; 3:73-8.

31. Armfield JM. How do we measure dental fear and what are we measuring anyway? Oral Health Prev Dent. 2010; 8:107-15.

32. Porritt J, Buchanan H, Hall M, Gilchrist F, Marshman Z. Assessing children's dental anxiety: a systematic review of current measures. Community Dent Oral Epidemiol. 2013; 41:130-42.

33. Al-Namankany A, De Souza M, Ashley P. Evidence-based dentistry: analysis of dental anxiety scales for children. $\mathrm{Br}$ Dent J. 2012; 12:219-22.

34. Rebok G, Riley A, Forrest C, Starfield B, Green B, Robertson J Et al. Elementary school-aged children's reports of their health: a cognitive interviewing study. Qual Life Res. 2001; 10:59-70.

35. Quteish DS. Dental anxiety and regularity of dental attendance in younger adults. J Oral Rehabil. 2002; 29: 6048.

36. Ma L, Wang M, Jing Q, Zhao J, Wan K, Xu Q. Reliability and validity of the Chinese version of the Children's Fear
Survey Schedule-Dental Subscale. Inter J Paediatr Dent. 2015; 25:110-6.

37. Bajrić E, Kobašlija S, Jurić H. Reliability and validity of Dental Subscale of the Children's Fear Survey Schedule (CFSS-DS) in children in Bosnia and Herzegovina. Bosn J Basic Med Sci. 2011; 11:214-8. 